\title{
Direct observation of two dimensional trace gas distributions with an airborne Imaging DOAS instrument
}

\author{
K.-P. Heue ${ }^{1}$, T. Wagner ${ }^{2}$, S. P. Broccardo ${ }^{3}$, D. Walter ${ }^{1}$, S. J. Piketh ${ }^{3}$, K. E. Ross ${ }^{4}$, S. Beirle ${ }^{2}$, and U. Platt ${ }^{1}$ \\ ${ }^{1}$ Institut für Umweltphysik (IUP), Universität Heidelberg, Heidelberg, Germany \\ ${ }^{2}$ Max Planck Institut für Chemie, Mainz, Germany \\ ${ }^{3}$ Climatology Research Group, University of the Witwatersrand, Johannesburg, South Africa \\ ${ }^{4}$ Generation Environmental Management Department, Eskom Pty (Ltd), South Africa
}

Received: 26 March 2008 - Published in Atmos. Chem. Phys. Discuss.: 13 June 2008

Revised: 8 September 2008 - Accepted: 6 October 2008 - Published: 21 November 2008

\begin{abstract}
In many investigations of tropospheric chemistry information about the two dimensional distribution of trace gases on a small scale (e.g. tens to hundreds of metres) is highly desirable. An airborne instrument based on imaging Differential Optical Absorption Spectroscopy has been built to map the two dimensional distribution of a series of relevant trace gases including $\mathrm{NO}_{2}, \mathrm{HCHO}, \mathrm{C}_{2} \mathrm{H}_{2} \mathrm{O}_{2}, \mathrm{H}_{2} \mathrm{O}, \mathrm{O}_{4}, \mathrm{SO}_{2}$, and $\mathrm{BrO}$ on a scale of $100 \mathrm{~m}$.

Here we report on the first tests of the novel aircraft instrument over the industrialised South African Highveld, where large variations in $\mathrm{NO}_{2}$ column densities in the immediate vicinity of several sources e.g. power plants or steel works, were measured. The observed patterns in the trace gas distribution are interpreted with respect to flux estimates, and it is seen that the fine resolution of the measurements allows separate sources in close proximity to one another to be distinguished.
\end{abstract}

\section{Introduction}

Several methods exist to retrieve two dimensional trace gas distributions in the atmosphere on various scales. Satellite observations lead to two dimensional distribution patterns on a global scale; however, the resolution is still rather coarse (several tens of $\mathrm{km}$ ). On smaller scales (several $\mathrm{km}$ ) tomographic inversion methods have been applied. The resolution of this method strongly depends on the number of light paths, therefore a fine resolution can only be achieved by installing a large number of instruments (Hartl et al., 2006). With the new airborne imaging Differential Optical Absorption Spectrometer (iDOAS), trace gas distributions can be observed

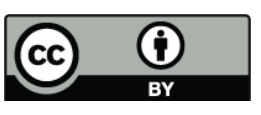

Correspondence to: K.-P. Heue

(klaus-peter.heue@iup.uni-

heidelberg.de) directly at a resolution of less than $100 \mathrm{~m}$. The main species to be observed with iDOAS are $\mathrm{NO}_{2}, \mathrm{HCHO}, \mathrm{C}_{2} \mathrm{H}_{2} \mathrm{O}_{2}, \mathrm{H}_{2} \mathrm{O}$, $\mathrm{O}_{4}, \mathrm{SO}_{2}$, and $\mathrm{BrO}$. Based on the observed patterns, sources and sinks can be quantified and chemical processes including conversion rates and atmospheric lifetimes may be analysed.

The BrO formation in volcanic plumes has been studied using ground-based iDOAS measurements (Bobrowski et al., 2007). On a larger scale satellite data have been used to quantify the strength of ship emissions based on SCIAMACHY $\mathrm{NO}_{2}$ distribution patterns in the Indian Ocean (Beirle et al., 2004).

Due to the high spatial resolution of the airborne iDOAS instrument, independent sources located close to one another may be resolved and quantified separately. The results can be used for satellite and chemical transport model validation. The variability within a satellite pixel is one of the major issues that might be addressed with the imaging DOAS instrument.

Results of tests of the iDOAS over the South African interior plateau, called the Highveld, are reported in this paper. The Highveld is the most industrialised region in southern Africa (Fig. 1), and satellite-detected $\mathrm{NO}_{2}$ column densities over the Highveld are the highest in the Southern Hemisphere; equivalent to those in the highly industrialised regions of east Asia, the Middle East, Europe and North America (Beirle et al., 2006). Large power plants, both conventional and synfuel refineries, metallurgical smelters, industries, mines and urban conglomerates on the Highveld are large area and point sources of pollution. Stable atmospheric conditions during winter inhibit dispersion and plumes tend to remain confined at large distances downwind of the sources. The Highveld is an ideal location to test the operation of a high resolution instrument like the airborne iDOAS.

Published by Copernicus Publications on behalf of the European Geosciences Union. 


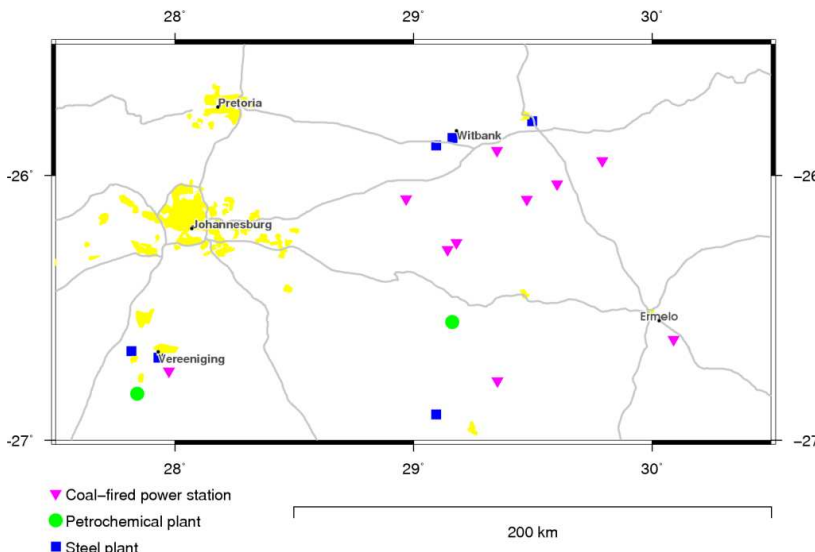

- Steel plant

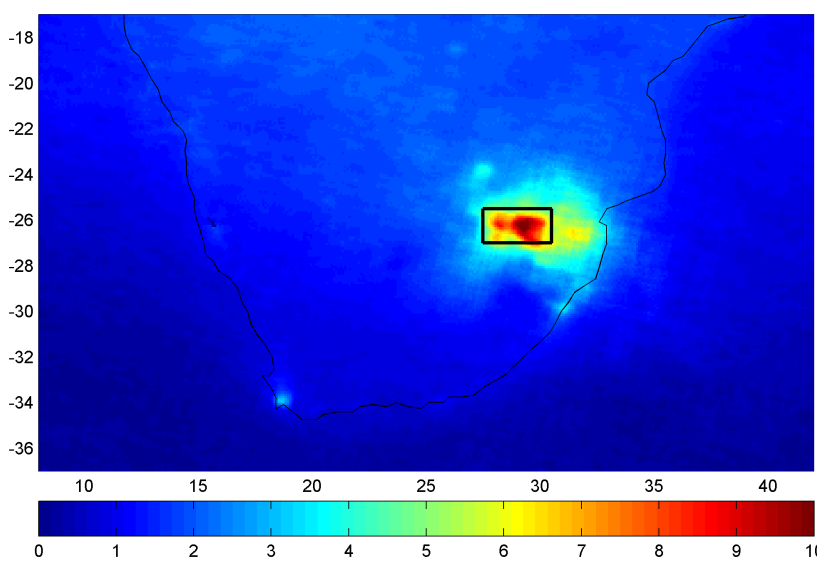

Fig. 1. Map of the Highveld including the position of the main industries. Mean tropospheric vertical $\mathrm{NO}_{2}$ column in $10^{15} \mathrm{molec} / \mathrm{cm}^{2}$ from SCIAMACHY measurements 2003-2007. The rectangular in the mean VCD map indicates the position of the details shown in the upper picture.

\section{The measurement technique}

The imaging DOAS technique was previously used in ground based applications (Lohberger et al., 2004; Bobrowski et al., 2007) to map the trace gas distribution resulting from stack and volcano emissions. For that purpose the instrument was directed towards the object of interest (Fig. 2). One section or column of the scene is imaged on the entrance slit of the spectrograph. The reflected and scattered sunlight is spectrally dispersed, and recorded by a charge-coupled device (CCD). Each line of the CCD chip corresponds to a spectrum and using the DOAS technique (Sect. 2.3) one trace gas slant column density is retrieved.

The DOAS analysis yields a slant column density (SCD) which is the integrated concentration along the light path (Sect. 2.3). In such a way, one section (column) of the respective trace gas distribution is observed. To obtain the two dimensional distribution of the slant column densities the instrument scans the scene perpendicular to the entrance slit (Fig. 2).

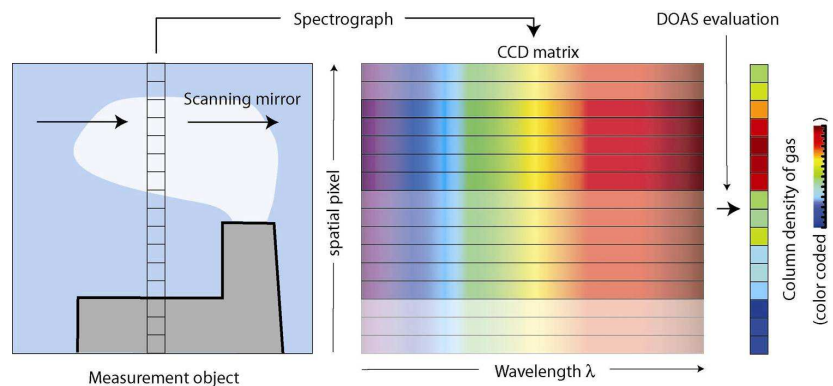

Fig. 2. Principle of the imaging DOAS technique (Lohberger et al., 2004).

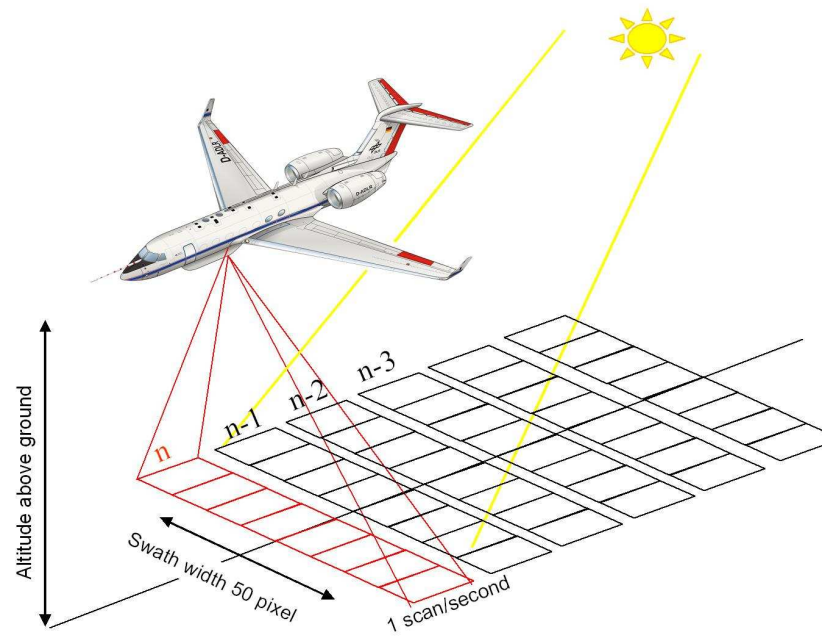

Fig. 3. Sketch of the airborne iDOAS technique.

\subsection{Instrumental setup}

The imaging DOAS instrument consists of an imaging spectrograph and a two dimensional detector i.e. a CCD camera. An optical system in front of the spectrograph focuses the incoming radiance onto the entrance slit. A large field of view $\left(28.8^{\circ}\right)$ is mapped on the spectrograph. The height $h$ of the entrance slit and the focal length $f$ of the entrance optics determine the field of view $\gamma$ :

$\tan (\gamma / 2)=\frac{h}{2 \cdot f}$

The instrument is installed on the aircraft with the entrance slit perpendicular to the flight direction. The entrance optics generate a swath perpendicular to the flight direction; this technique is called pushbroom imaging. The light entering the spectrograph is spectrally analysed, and detected by the CCD. DOAS analysis of the recorded spectra yields one across-track column of trace gas information. The principle is illustrated in Fig. 3.

The aeroplane moves forward while a column of trace gas information is being recorded; the resolution parallel to the 


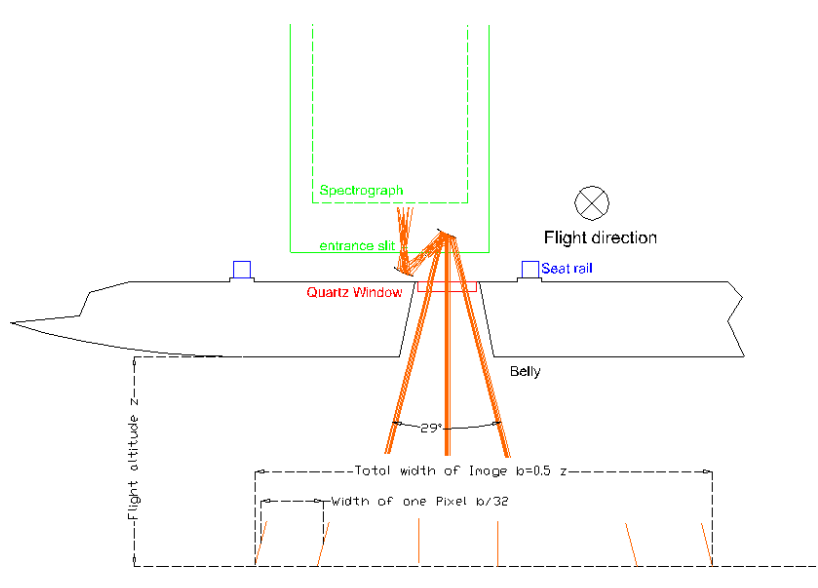

Fig. 4. Details of the mirror based entrance optics viewed from the back of the aircraft. The total swath width equals half the flight altitude and is divided into 32 pixels. Due to obstruction from the belly only 27 pixels receive a significant signal.

flight direction is determined by the speed of the aircraft and the exposure time. After data from the CCD has been read out the next set of spectra is recorded. In the mean time the trace gas contribution below the aircraft may have changed. In such a way, information about the two dimensional trace gas distribution below the aeroplane can be gained.

The resolution perpendicular to the flight direction is determined by the magnification of the optical system and the numbers of lines on the CCD chip i.e. 255 for our instrument. However due to the imperfect imaging qualities of the system (Sect. 2.2) 8 lines have to be co-added, thus reducing the resolution to 32 lines perpendicular to the flight direction. Moreover to a certain degree the signal to noise ratio is improved, and the detection limit reduced, when several CCD lines are co-added. This only holds when the calibration and the slit functions of the added lines are similar, otherwise additional errors are introduced into the DOAS fit.

The instrumentation used for this study consists of an ACTON 300i imaging spectrograph, which is a Czerny-Turner type with $300 \mathrm{~mm}$ focal length, an Andor DU-420BU CCD with $255 \times 1024$ pixel, and mirror-based entrance optics.

Details of the optical system are illustrated in Fig. 4. The first mirror is convex with a focal length of $51.5 \mathrm{~mm}$ and the second one is concave and has $25.6 \mathrm{~mm}$ focal length. The combination of the two mirrors placed $70 \mathrm{~mm}$ apart results in the focal length of $13.7 \mathrm{~mm}$. The entrance slit is $6.9 \mathrm{~mm}$ high, and according to Eq. (1) the total field of view is $28.8^{\circ}$. Therefore the total swath width at the ground equals half the flight altitude above ground level (a.g.l.). As the sensitivity of the DOAS measurement strongly depends on the length of the light path, one might think that it would be more sensitive towards the edges of the images. However if the geometrical light path at the edges is compared to the nadir (centre), it is enhanced by $1 / \cos \left(14^{\circ}\right)=1.03$ i.e. only $3 \%$. In the air mass

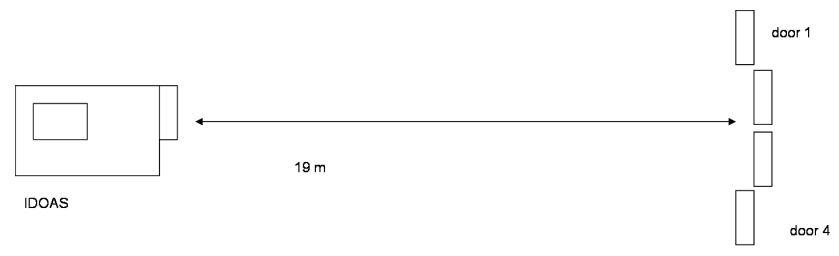

Fig. 5. Ground setup used to characterise the optical properties of the airborne iDOAS. Each hangar door was $4.5 \mathrm{~m}$ wide and the small openings in between were $30 \mathrm{~cm}$, hence the total distance between the 3 light sources was $9.9 \mathrm{~m}$ (edge to edge).

factor calculation (Sect. 2.3) no differences in the sensitivity for the individual light paths is observed.

In contrast to the ideal setup illustrated in Fig. 4, the quartz window in the aeroplane was a little bit too small, reducing the field of view to $24^{\circ}$. Each swath was divided into 27 ground pixels instead of 32. Assuming a standard flight altitude of $4500 \mathrm{~m}$ a.g.l., the total swath was $1910 \mathrm{~m}$ wide and the lateral resolution was $71 \mathrm{~m}$.

\subsection{Characterisation of the instrument}

To characterise the imaging quality of the instrument several tests with different light sources were performed. Most artificial light sources had to be installed rather close to the instrument, hence the optical system tests were made under slightly different conditions to the real measurements. One of the most convincing tests was to set up the instrument inside the hangar and direct it towards the doors. Each of the four doors was $4.5 \mathrm{~m}$ wide and the distance to the instrument was $19 \mathrm{~m}$. If the doors were opened by $30 \mathrm{~cm}$, it resulted in three vertically extended light sources of $30 \mathrm{~cm}$ width separated by $4.5 \mathrm{~m}$ at a distance of $19 \mathrm{~m}$ from the instrument (Fig. 5). The instrument's total field of view is $9.5 \mathrm{~m}$ wide at the doors position. A light source of $30 \mathrm{~cm}$ width at a distance of $19 \mathrm{~m}$ is expected to result in a spectrum of 255 pixels $/ 9.5 \mathrm{~m} \cdot 0.3 \mathrm{~m} \approx 8$ pixels on the CCD. The observed image is shown in Fig. 6. The central spectrum has a full width of half maximum (FWHM) of 8 pixels. If the light source was made smaller (by closing the doors slightly) only a small decrease was observed, whereas if the doors were opened a clear increase in the width of the spectra was visible. Therefore the minimum resolution of the complete system is approximately 8 pixels or $0.88^{\circ}$.

The minimum resolution along the flight direction is also determined by the optical system. If the motion of the plane is ignored or integration time is infinitely small, the instantaneous resolution would be $20 \mathrm{~m}$ at a flight altitude of $4500 \mathrm{~m}$ a.g.l. $\left(\alpha=0.25^{\circ} ; 60 \mu \mathrm{m}\right.$ slit width). This has to be added to the distance the plane travels during the actual integration time (Eq. 2). In total the typical resolution ranges between $90 \mathrm{~m}$ and $200 \mathrm{~m}$. A small gap $(20 \mathrm{~m})$ between the individual scans was caused by the CCD readout procedure, 


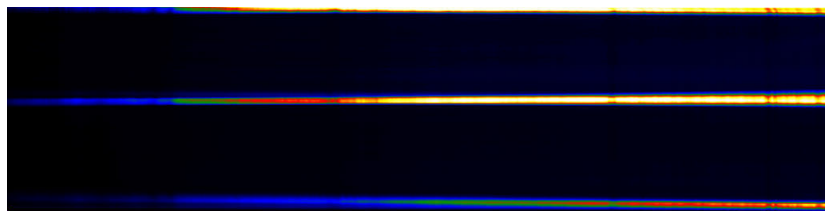

Fig. 6. CCD image of the three hangar doors. Only parts of the outermost slits are observed. This is expected as the distance between the doors and the instrument is less than double the distance between light sources. The total chip is 255 lines wide and the illuminated area in the centre covers 8 lines.

which lasted $0.4 \mathrm{~s}$. The width of the gap also depends on the flight altitude (Eq. 3); if the plane is flying lower the gap is bigger, but the minimum resolution perpendicular to the flight direction gets finer (Fig. 11). For a given ground speed $v$, an integration time $t$ and the flight altitude $h$ the total length $l$ of a pixel is:

$l=v \cdot t+2 \cdot h \cdot \tan \left(\frac{\alpha}{2}\right)$

and the length of the gap between pixels is:

$l=v \cdot 0.4-2 \cdot h \cdot \tan \left(\frac{\alpha}{2}\right)$

The iDOAS instrument was installed on the Rockwell Aerocommander 690A operated by the South African Weather Service. The standard flight altitude was $6 \mathrm{~km}$ a.m.s.l (above mean sea level) or $4.5 \mathrm{~km}$ a.g.l.; the speed ranged from $95 \mathrm{~m} / \mathrm{s}$ to $135 \mathrm{~m} / \mathrm{s}$. The typical integration time was about $1 \mathrm{~s}$ or less, hence the spatial resolution in the flight direction is about $100 \mathrm{~m}$. The integration time is determined automatically so the spectra have $\approx 70 \%$ of the saturation level.

The determination of the instrument's exact field of view relative to the aeroplane is not straightforward, although some measurements were performed while the aircraft was on the ground. The accuracy of these measurements is limited by the short distance of $\approx 60 \mathrm{~cm}$ between the instrument and the ground. Therefore the viewing direction is uncertain, even if the roll and pitch angles were available. Based on this method the accuracy of the field of view is $\approx 5^{\circ}$, at our standard flight altitude this equals $393 \mathrm{~m}$ or more than 5 pixels at ground level. For this study we determined the field of view by comparing a black and white image derived from the our measurement with precise satellite pictures e.g. from Google Earth. The error is thereby reduced to about $1^{\circ}$, which is approximately the size of one or two pixels.

\subsection{DOAS technique}

To retrieve column densities from the observed spectra, the well known DOAS technique (Platt, 1994) is applied. The method is based on Lambert-Beer's law. The absorption cross section $(\sigma)$ is a characteristic function of the wavelength $\lambda$ for the individual trace gases. The integrated concentration along the light path is called slant column density and is the result of the DOAS analysis. A normal in-flight spectrum in a remote and clean area is usually taken as the reference for the analysis, allowing the Fraunhofer structures to be removed from the DOAS-fit and the stratospheric background concentration to be subtracted. To select a good reference spectrum several aspects have to be considered i.e. the aircraft having reached the standard cruising altitude, there being no clouds below the aeroplane, and the spectrum being neither too dark nor saturated. However, if this remote region has a non-zero concentration of the absorber, parts of the tropospheric signal will subtracted as well. Hence the results presented in Sect. 3 are based on the differences between the local true column densities and the column density of the reference. They are usually referred to as differential slant column densities and constitute the lower limit of true tropospheric slant column densities. A correction has to be added to the differential slant column density after the analysis to correct for any $\mathrm{NO}_{2}$ in the area of the reference spectrum, here the OMI data from the reference area were used to estimate this correction.

The wavelength range between 467 and $517 \mathrm{~nm}$ was chosen for the analysis and, besides $\mathrm{NO}_{2}$, (Vandaele et al., 1997) the cross sections of water vapour (Rothman et al., 1998), $\mathrm{O}_{4}$ (Hermans et al., 1999) and $\mathrm{O}_{3}$ (Burrows et al., 1999) were included. The filling in of the Fraunhofer lines due to inelastic Raman scattering (Ring effect) (Grainer and Ring, 1962) was considered by using an appropriate cross section (Gomer et al., 1996). The instrumental function varies across the CCD chip in both dimensions. Therefore individual reference and ring spectra are applied in the fit for the spectra recorded in the respective regions of the CCD-chip. Moreover an individual calibration was used for each line. For the central CCD line a $\mathrm{NO}_{2}$ fit is shown in Fig. 7. The spectrum was recorded on 5 October 2006 close to the synfuels refinery in Secunda (Figs. 9 and 10). The retrieved data is equivalent to the integrated concentration along the light path - the SCD. The tropospheric vertical column density (tVCD) gives the integrated concentration across the altitude up to the mixing layer height independent of the light path. The ratio between slant and vertical column is called the air mass factor (AMF). It has to be simulated using a radiative transfer model. The complete light path between the instrument and the sun has to be considered for the model calculation. In this case the Monte-Carlo based radiative transfer model McArtim (T. Deutschmann, Univ. Heidelberg, Germany, diploma thesis to be submitted, 2008) was used. The geometry of the setup including solar zenith angle was considered and the terrain altitude $(1500 \mathrm{~m})$ was included. The altitude is not quite correct for the entire Highveld, but within a range of $200 \mathrm{~m}$ no altitude dependency was observed in the simulation. An aerosol extinction of $0.2 \mathrm{~km}^{-1}$ at ground level and $0.1 \mathrm{~km}^{-1}$ at the top of the Mixing layer $\approx 2000 \mathrm{~m}$ a.g.l. is assumed. Especially in dense plumes, aerosols can reduce the visibility; however this effect was ignored here, as no significant change in the $\mathrm{O}_{4}$ observation was detected. Due to emissions 


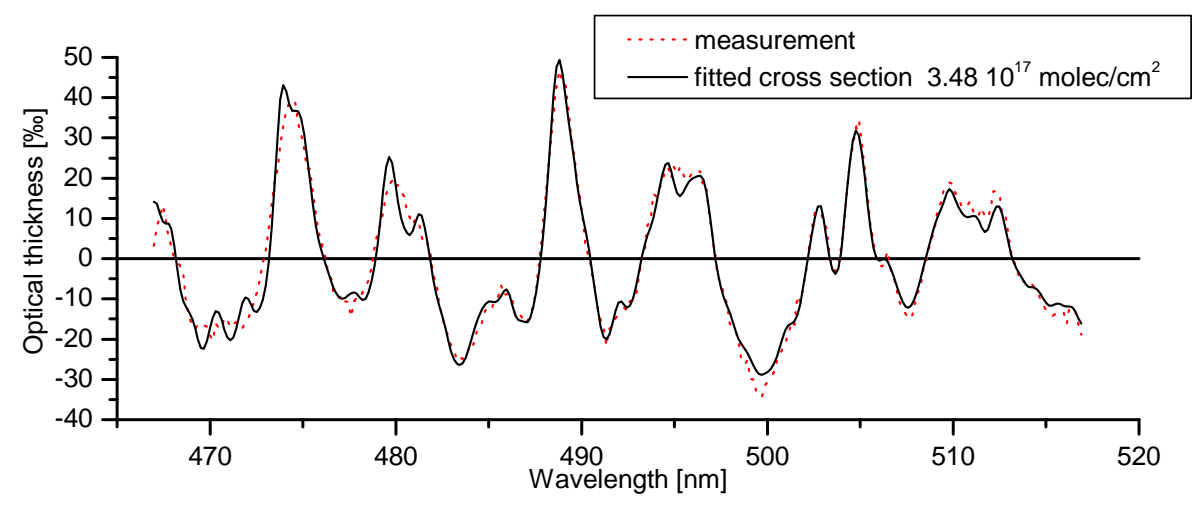

Fig. 7. Example fit of the DOAS analysis for $\mathrm{NO}_{2}$. The analyzed spectrum was observed on 5 October 2006 downwind of Secunda synfuel refinery (spectrum 1355 line 16).

of water vapour, clouds can sometimes be observed above power plants. This was not the case in the dry season on the Highveld. The cloud coverage was low, especially in the interesting areas, hence clouds were not taken into account for the AMF calculation.

Depending on the plume altitude and thickness two different pollution scenarios were considered, in the urban areas or downwind of the source a constant concentration in the mixing layer is an adequate approximation, close to the sources a constant concentration between $400 \mathrm{~m}$ and $800 \mathrm{~m}$ is a better description of the real conditions. However the differences in the AMF between these two pollution scenarios was very small and is therefore neglected. The flight altitudes given in Table 1 were also included, when flying at higher flight altitudes $\approx 6000 \mathrm{~m}$ the AMF hardly changed with altitude. The highest instrument sensitivity is achieved when the aeroplane is close to the mixing layer altitude. Inside the mixing layer part of the plume is above the plane and the AMF decreases rapidly (Fig. 8). During the observation the Solar Zenith Angle (SZA) changed between $20^{\circ}$ and $40^{\circ}$ in this range the AMF for the flight altitude of $6000 \mathrm{~m}$ increased from 1.7 to 1.9 .

\section{Results}

\subsection{First measurements}

Three test flights over large pollution sources (coal-fired power plants, steel works and refineries) on the Highveld were flown on 4, 5 and 6 October 2006 (Table 1). To test the imaging DOAS the flights lead to many point sources where small scale variations were to be expected. To minimize a change in the observation due to solar zenith the flights were performed around noon. The $\mathrm{NO}_{2}$ column densities showed strong gradients in the immediate vicinity of various sources. An overview of the flight track from the first and the second flight (4 and 5 October 2006) is shown in Fig. 9. The

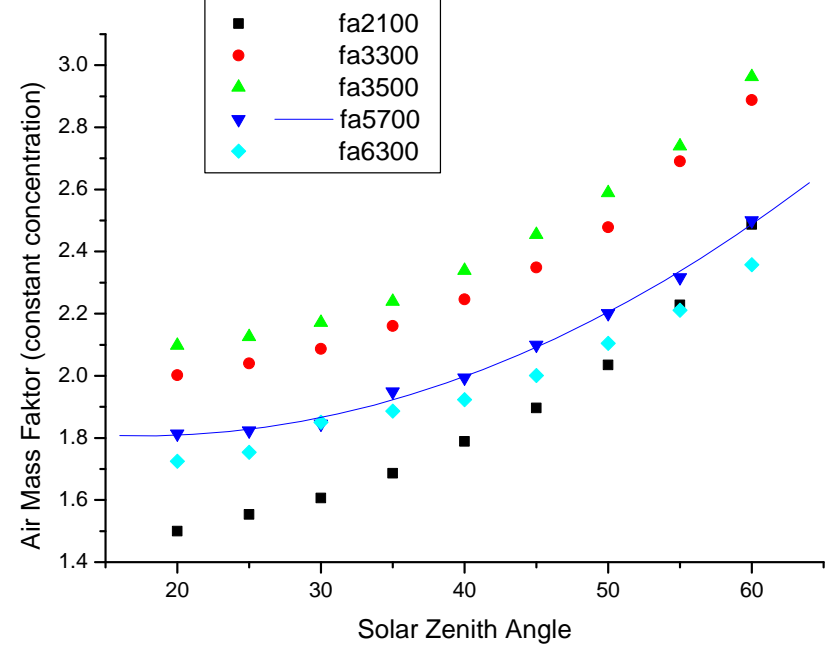

Fig. 8. Air Mass Factors for different flight altitudes (fa in $m$ above mean sea level) as a function of the solar zenith angle.

flight track and the observed $\mathrm{NO}_{2}$ column densities of the third flight are compared to SCIAMACHY and OMI data in Fig. 15. Enhanced $\mathrm{NO}_{2}$ column densities are observed downwind of the plants. In both figures no gradients in the column densities perpendicular to the flight direction are shown, the thickness of the lines does not correlate to swath width but is just a point in the plotting tool. In Fig. 9 the nadir data (CCD-line 16) are shown and in Fig. 15 the average VCDs for all CCD lines are illustrated.

During the 2nd flight (Fig. 9) the plume from Kendal power station was observed to merge with the plumes from Matla and Kriel power stations to form one large plume which broadened with distance downwind. The plume of the synfuels refinery in Secunda was crossed three times at different distances downwind of the plant. The plume from the refinery is also observed to broaden and become more diffuse with distance from the source. 
Table 1. Overview on the three test flights. The local time is GMT $+2 \mathrm{~h}$, so all the flights were performed around noon. The standard flight altitude is given first, descents were flown to look for the boundary layer height

\begin{tabular}{rrrrr}
\hline Date & $\begin{array}{r}\text { Time } \\
\text { GMT }\end{array}$ & SZA & $\begin{array}{r}\text { flight altitude } \\
{[\mathrm{m}] \text { a.m.s.l. }}\end{array}$ & weather conditions \\
\hline 04.10 .2006 & $10: 30-12: 00$ & $26-38$ & 3300 and 2100 & some clouds in the south \\
05.10 .2006 & $09: 30-12: 45$ & $22-41$ & 5700 and $3600 \quad$ clouds in the south, boundary layer at $3600 \mathrm{~m}$ \\
06.10 .2006 & $09: 30-12: 00$ & $22-37$ & 6300 and $3900 \quad$ clouds $<1 / 8$, boundary layer at $3900 \mathrm{~m}$ \\
\hline
\end{tabular}

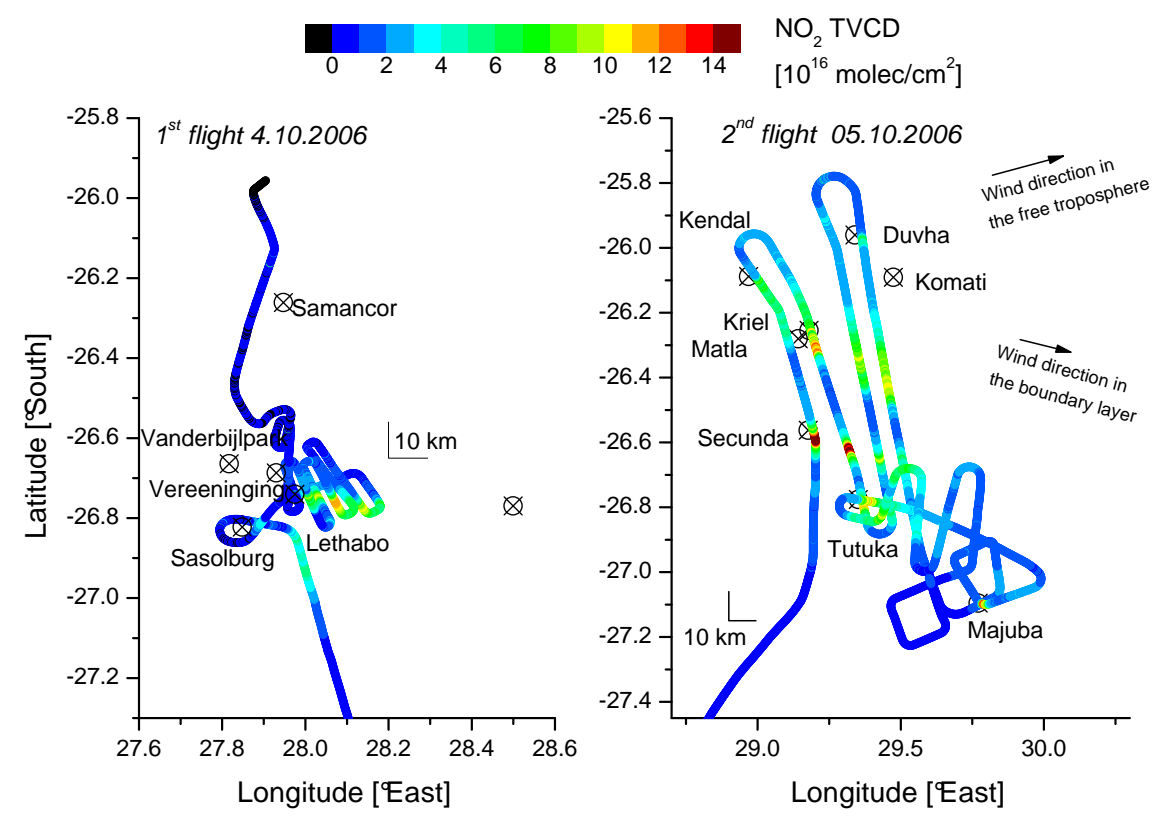

Fig. 9. Overview of the tracks of the flight on 4 and 5 October 2006 close to pollution sources. The tracks are colour coded (the same colour code is used for both figures) to indicate the $\mathrm{NO}_{2}$ vertical column density in nadir. The thickness of the line does not represent the true swath width.

\subsection{Two dimensional $\mathrm{NO}_{2}$ distributions}

Detailed 2-D images of the $\mathrm{NO}_{2} \mathrm{VCD}$ close to selected sources are shown in Figs. 10, 11 and 12. To focus on the small scale variations no reference correction was added to the vertical column densities depicted in these figures. In Fig. 12 the local background was subtracted to prepare the flux calculation in Sect. 3.3

In Fig. 10 the mixing of $\mathrm{NO}_{2}$ plumes originating from different sources in Secunda is visible. The two plumes extend in different directions, which allows a qualitative altitude determination. The smaller one is advecting more perpendicular to the flight direction, and according to the Eckman spiral of wind direction, this plume can be expected to be at a higher level than the large plume.

The spatial resolution at ground level theoretically increases when the flight altitude is lower. However, most of the point sources observed here do not emit at ground level but from a stack approximately $250 \mathrm{~m}$ above the ground. As the exit temperature of the emitted gases is usually quite high (on the order of $130^{\circ} \mathrm{C}$ for coal-fired power stations), effective stack height is several hundred metres above actual stack height, and there is a risk of missing the plume or observing only parts of it when flying at lower altitudes.

On 4 October 2007 the aircraft flew over Lethabo power plant in the Vereeniging area south of Johannesburg at $600 \mathrm{~m}$ a.g.l. (stack height $275 \mathrm{~m}$; Fig. 11). The local enhancement in $\mathrm{NO}_{2}$ column densities is observed in only a few pixels. Just north of the plant, high intensity of reflected light (probably caused by the cooling tower or the saturated plume above it) led to a blooming effect on the CCD, therefore no valid observation was made here. Although the plume was observed directly beneath the aeroplane and partly downwind, no widening of the plume perpendicular to the wind direction 


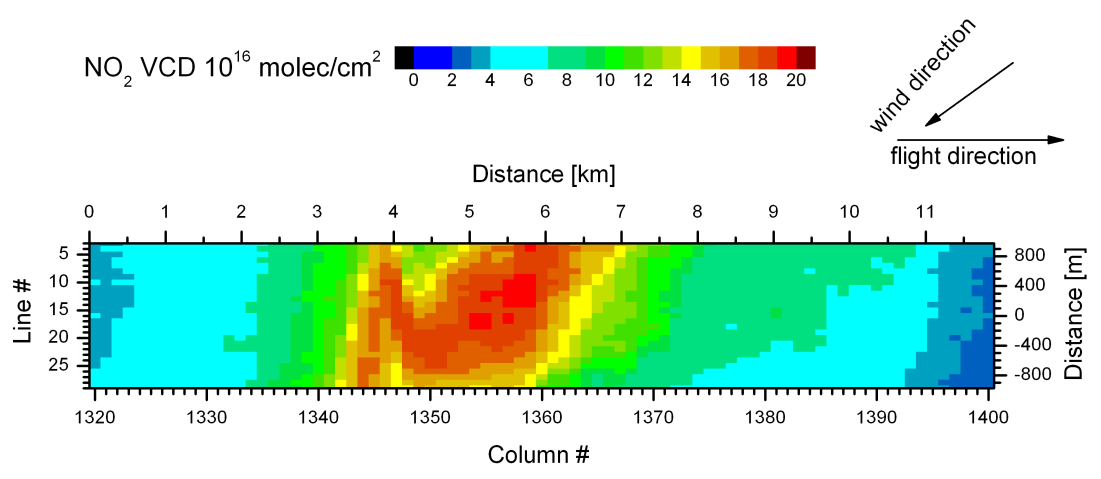

Fig. 10. $\mathrm{NO}_{2}$ VCD close to the synthetic fuel refinery in Secunda, showing the mixing of two plumes (Heue et al., 2007). Both plumes probably originate from the refinery but from different sources, however they can clearly be resolved. The gaps between the individual columns are not shown (like in Fig. 11) as they are rather small due to the high flight altitude

is observed. The plume either broadens by less than one pixel $(\approx 100 \mathrm{~m})$ at $150 \mathrm{~m}$ downwind of the stack, or it widens above the flight level and the effect cannot be observed by the downward looking imaging DOAS. Nevertheless the high resolution of $10 \mathrm{~m}$ perpendicular to the flight direction is astonishingly good.

A typical plume expansion is observed close to the Majuba power plant (Fig. 12 top). To correct for a slightly enhanced background, the averaged column densities downwind of the power plant (first 8 lines of the image) were subtracted. In Fig. 12 (bottom) the image is overlaid on a local satellite image from Google Earth. A strong enhancement in the $\mathrm{NO}_{2}$ column is observed close to the stack. This is probably caused by the long absorption path when looking on a rising plume from above. Further downwind the plume widens and the local column densities decrease as the plume turns from vertical to horizontal. The local enhancement at the downwind edge of the image is not yet fully understood but seems to be a real change in the slant column density. It may be caused by the oxidation of $\mathrm{NO}$ to $\mathrm{NO}_{2}$ in the plume driven by the mixing in of $\mathrm{O}_{3}$. Nitrogen oxides are mostly emitted as $\mathrm{NO}$ rather than $\mathrm{NO}_{2}$, typically $95 \%$ is $\mathrm{NO}$. By reaction with $\mathrm{O}_{3}$ it converts to $\mathrm{NO}_{2}$ until the well known Leighton ratio establishes.

If the plume expands in vertical waves, this might again result in a locally extended absorption path through the plume. As the increase in the column density is higher than $3 \%$ the observation is not caused by the systematic difference in the sensitivity (Sect. 2.1). The position of the stack in Fig. 12 is determined based on the method described in Sect. 2.2.

\subsection{Flux estimate}

Based on the local $\mathrm{NO}_{2}$ column densities close to Majuba power station (Fig. 12) the flux was estimated. For selected distances downwind of Majuba the cross sections of the vertical column densities are illustrated in Fig. 13. The maximum of the column density is observed close to the stacks as
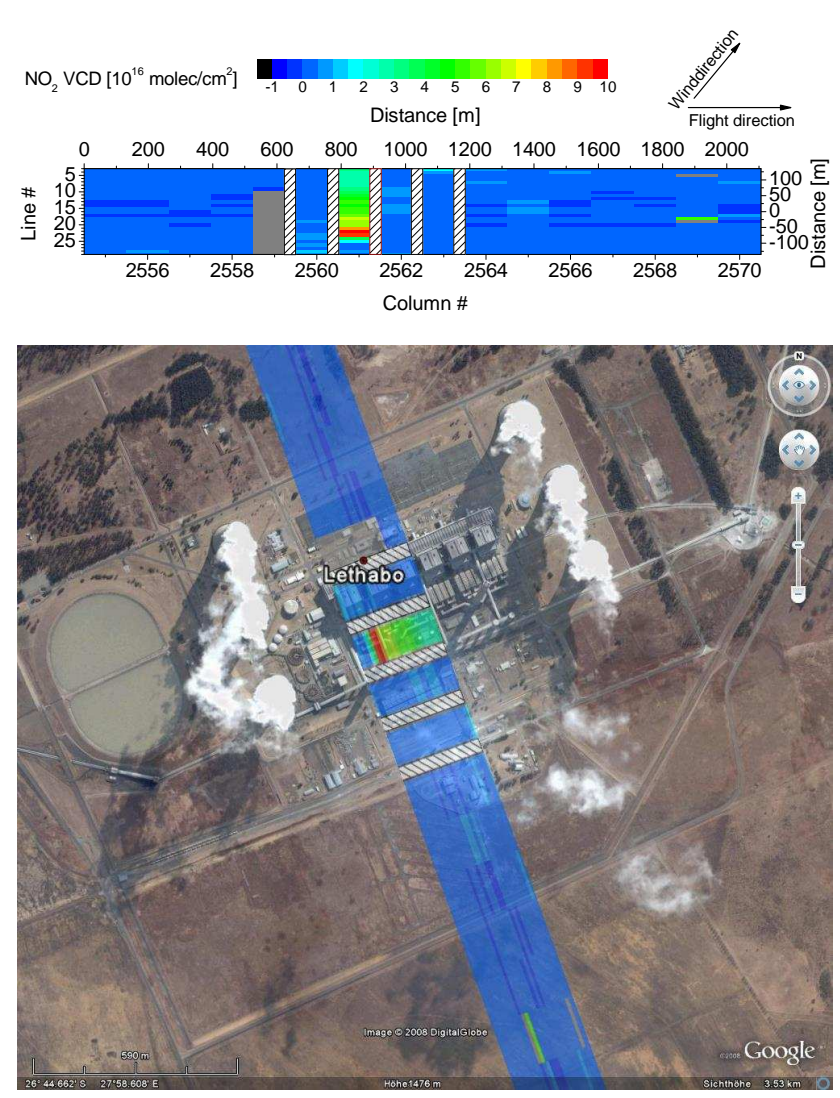

Fig. 11. Enhanced $\mathrm{NO}_{2}$ VCDs over the stack of Lethabo power station 4 October 2006. The CCD was partly oversaturated leading to a blooming effect; hence no data are shown just north of the plant. No spectra are observed during the read out process indicated by the hashed areas. This also holds for the rest of the observation but is only shown close to the power plant. Compared to Fig. 10 and Fig. 12 the flight altitude is significantly lower, therefore the pixels are smaller here. An overlay to a Google Earth map is shown in the lower panel. 

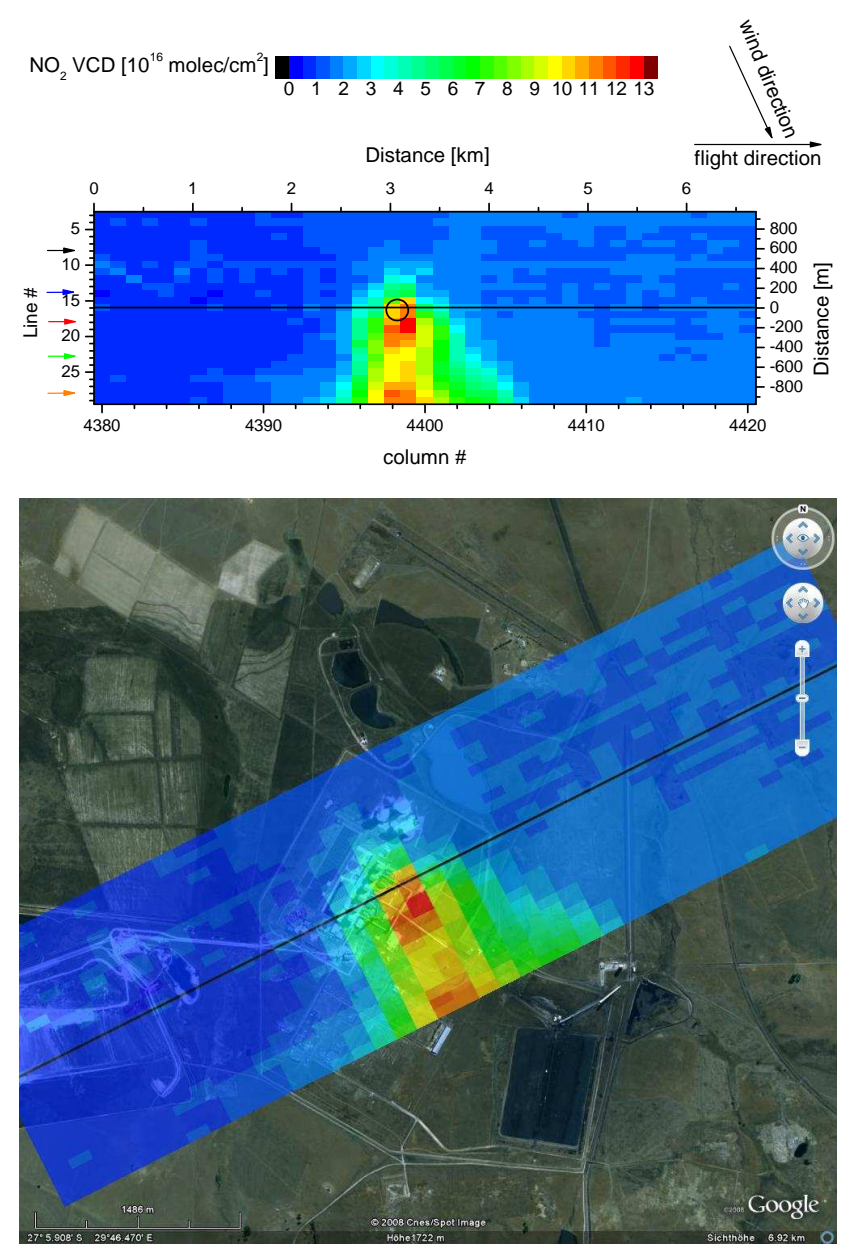

Fig. 12. $\mathrm{NO}_{2} \mathrm{VCD}$ (top) around the Majuba power plant (5 October 2006) overlay over a local map (bottom). Same flight level as Fig. 10, hence the pixels are wide again and the gaps are not shown. The arrows in the top figure indicate the position of the respective cross sections shown in Fig. 13. The circle shows the approximate position of the plant.

mentioned above. The maximum flux (Fig. 14) however, is further downwind when the plume is wider.

The flux was estimated by integrating the vertical column densities (VCD) along the local flight track (x-direction in formula of Eq. 4) considering the local wind speed $v_{\text {wind }}$ and wind direction $\alpha_{\text {wind }}^{\text {flightdirection }}$ relative to flight direction:

$\Phi=\int \operatorname{VCD}(x) \cdot v_{\text {wind }} \cdot \sin \left(\alpha_{\text {wind }}^{\text {flightdirection }}\right) \cdot d x$

The wind speed was not measured on board the aeroplane but hourly averaged ground based observations are available from Majuba. The wind on this day (5 October 2006) was rather calm and blew at approximately $2.2 \mathrm{~m} / \mathrm{s}$ from a north westerly direction $\left(\approx 296^{\circ}\right)$ between 10:00 and 12:00 UTC. The observed $\mathrm{NO}_{2}$ pattern (Fig. 12) however, indicates the wind direction was more from the north $\approx 330^{\circ}$. The tempo-

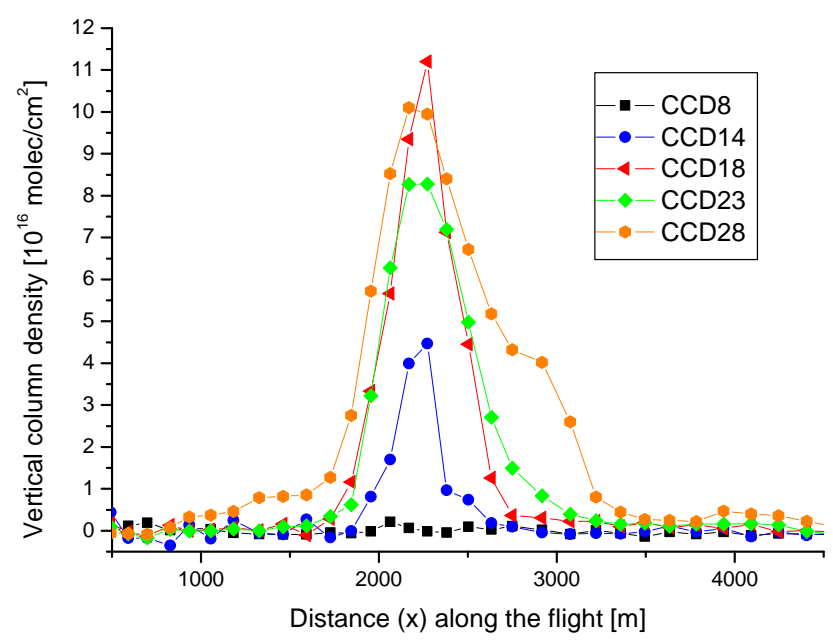

Fig. 13. Cross sections through the plume along the flight direction. The respective lines are indicated in Fig. 12.

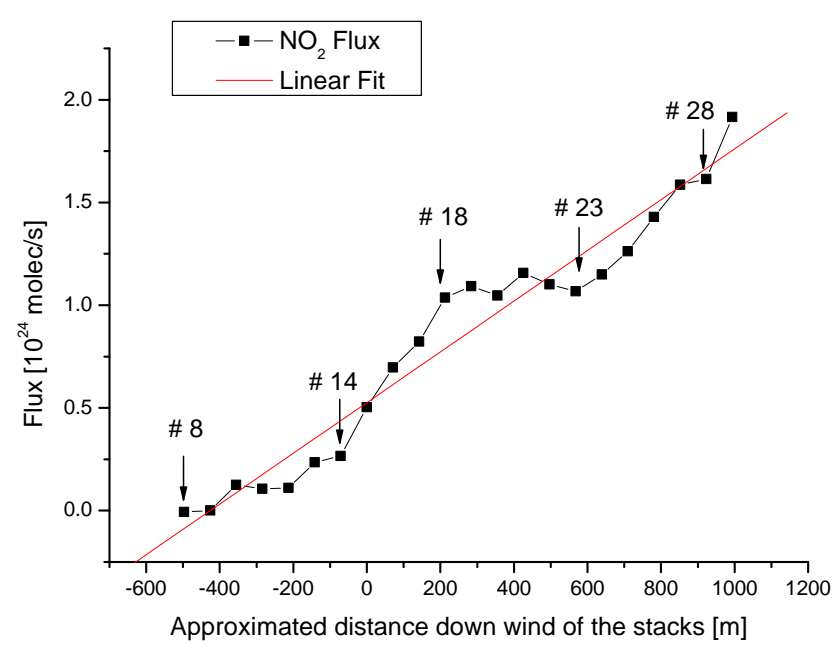

Fig. 14. $\mathrm{NO}_{2}$ flux downwind of the Majuba power plant. Upwind of the stack the $\mathrm{NO}_{2}$ columns are slightly enhanced. Perhaps the positions of the stacks are not known precisely enough or the low wind speeds allows some turbulent mixing close to the buildings.

ral variation in a $5 \mathrm{~min}$ interval can not be resolved by hourly averaged data, therefore during the measurements a northern wind direction does not contradict the measured wind direction in Majuba. Due to the high uncertainties in both methods the average wind direction $\left(\approx 313^{\circ}\right)$ is considered in the flux estimates. The course of the aeroplane at that time was $\approx 65^{\circ}$.

Downwind of the source a linear increase in the total $\mathrm{NO}_{2}$ flux is observed (Fig. 14). This of course does not necessarily indicate that additional sources are observed downwind, but it mainly results from the above mentioned NO oxidation and a parallel $\mathrm{O}_{3}$ destruction.

Upwind of the source the flux is not zero. This might be caused by turbulent mixing near the buildings. It might also 


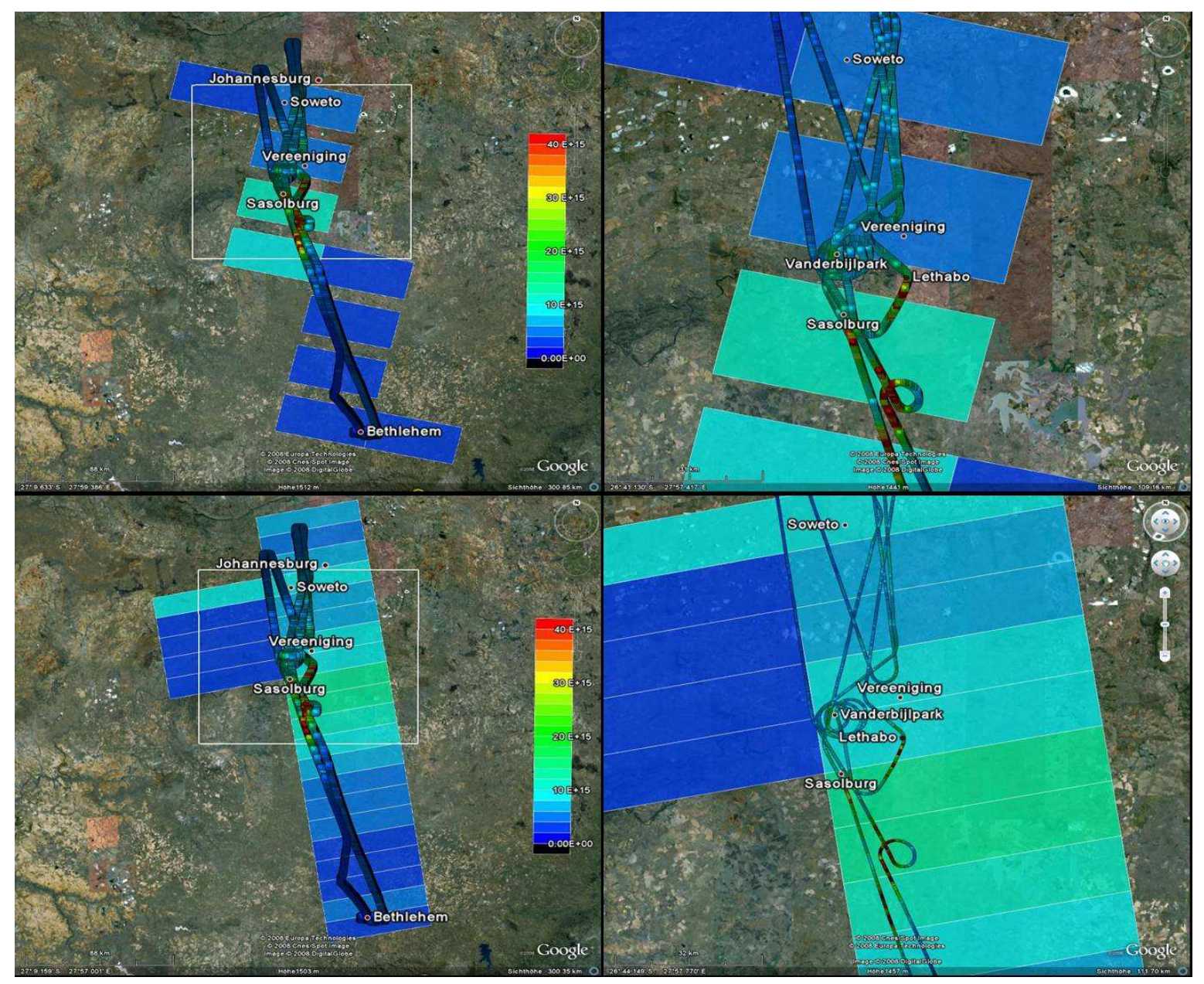

Fig. 15. Comparison between averaged iDOAS vertical column density data and the satellite VCD from SCIAMACHY (top) and OMI (bottom) from 6 October 2006. Strongly enhanced column densities were observed by the Imaging DOAS instrument in the industrial area around Vereeniging. Due to the large sampling area the local enhancement affect the satellite observations only slightly.

be caused by an insufficient background correction, although the flux further away from the plume is far less. Instrumental effects should also not be neglected here. The exact direction in which the instrument is pointed cannot be determined; therefore the position of the enhanced $\mathrm{NO}_{2}$ columns relative to the real source might be shifted by one or two pixels (up to $140 \mathrm{~m}$ ). Since resolution of the iDOAS instrument is quite good the observed increase cannot be explained by a sampling effect.

\subsection{Comparison with satellite data}

A first comparison of the iDOAS measurements with SCIAMACHY and OMI (www.temis.nl) tropospheric vertical columns is shown for the flight on 6 October 2006 in Fig. 15. The finer resolution iDOAS data can be averaged perpendicular to the flight direction for comparison with the satellite instrument. As the column densities close to the reference were estimated using OMI data the good agreement in the background level is expected.

South of Johannesburg in the industrial region around Vereeniging high column densities were observed. The enhanced local concentrations also lead to an increase in both satellite's $\mathrm{NO}_{2}$ data. The large field of view of SCIAMACHY however, is dominated by the low column densities outside the industrial areas. Also for OMI the resolution of these pixels (pixels 5 and 6, near the edge of the swath) is comparable. Hence we can estimate the $\mathrm{NO}_{2}$ variability inside the satellite pixels to be rather high, as the enhancement seems to be caused by high column densities in a small area, whereas the surrounding areas seems to be much cleaner. The latitudinal cross section of the vertical columns along the flight (Fig. 16) highlights the strong local gradients in the vicinity of the industrial complexes. However as the imaging DOAS measurements focused on the strong emitters very little information about the back ground column 


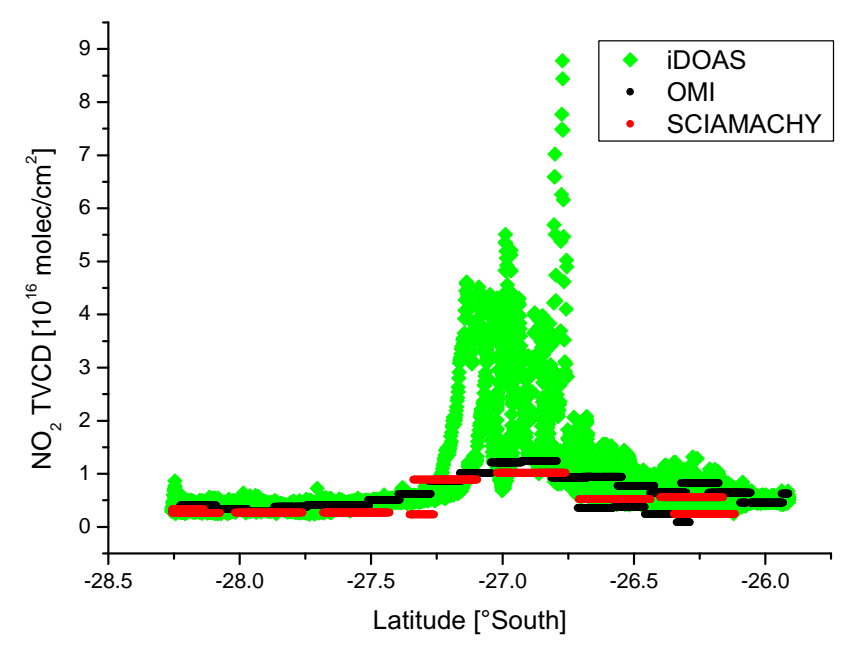

Fig. 16. Latitudinal cross section of Vertical column densities of the iDOAS and the satellite instruments SCIAMACHY and OMI from 6 October 2006 (Fig. 15). The strong enhancements close to the industrial areas and the local gradients are even more obvious in this illustration.

densities is available. Therefore a more detailed comparison e.g. calculating the averaged column density within a satellite ground pixel is not possible. For the detailed comparison with the SCIAMACHY data also the temporal mismatch has to be considered. The aeroplane arrived at Sasolburg at 09:55 and returned at 11:25 UTC. ENVISAT (SCIAMACHY) crossed the same a rea $2 \mathrm{~h}$ before at 07:46 UTC. Within these 2 morning hours the atmospheric conditions might have changed significantly. For the OMI observation the difference is $10 \mathrm{~min}$ to the second overpass of the iDOAS and might hence be neglected.

\section{Conclusions}

We presented the first direct observations of two dimensional $\mathrm{NO}_{2}$ distributions over the industrialised Highveld in South Africa. Based on the observed $\mathrm{NO}_{2}$ patterns two different sources in close proximity to one another can be distinguished, and a qualitative plume altitude determination can be made.

$\mathrm{NO}_{2}$ flux estimates are possible on the basis of vertical columns and wind data. Although the maximum column density decreases with distance from the stack, an overall increase in the $\mathrm{NO}_{2}$ flux is observed. The widening of the plume and the $\mathrm{NO}$ to $\mathrm{NO}_{2}$ conversion contribute to this effect. A radiative transfer model was used for the calculation of air mass factors; however, some three dimensional geometrical effects like a localised plume have not yet been considered. These data could also be compared to data provided by the plant operators.

Vertical column densities from the iDOAS were compared to satellite data (SCIAMACHY and OMI). Although the different spatial resolution of satellite instruments results in large discrepancies between finer resolution iDOAS measurements and coarser resolution satellite measurements (Heue et al., 2005), detailed knowledge about the local distribution inside the satellite pixels is of great interest. For a more quantitative comparison special flights have to be performed, during which the flight is coordinated with satellite overpass time and a special flight pattern is designed to study the local gradients in one pixel, i.e. observing both the sources and the background.

To improve the pointing accuracy of the iDOAS, a digital camera will be installed next to the spectrometer. This will give additional information on the area over which the flight is conducted.

The actual wavelength range of the instrument is optimised for $\mathrm{NO}_{2}$, but several interesting trace gases e.g. $\mathrm{SO}_{2}$ and HCHO show strong absorption bands in the UV (300$400 \mathrm{~nm}$ ). Future measurement flights will use a slightly different instrument optimised for the observation of these trace gases as well.

Additional measurement flights over the Highveld (South Africa) were performed in August 2007 and March 2008, in order to validate the satellite retrievals on a regional scale and investigate individual sources on a local scale. The analysis of this data is still in progress, but in the UV range other trace gases like $\mathrm{SO}_{2}$ and $\mathrm{HCHO}$ can be detected and at least for $\mathrm{SO}_{2}$ a similar resolution can be achieved close to the sources.

Acknowledgements. Financial support for this research project was provided by Eskom Corporate Services as part of their Research and Development Programme and is gratefully acknowledged. The work was also supported by the German federal ministry for science and education and the DLR project BMBF 50EE0501. OMI NRT data were provided by KNMI (The Netherlands) and were produced in collaboration with NASA (USA). OMI, a Dutch-Finnish built instrument, is a part of NASA's EOS-Aura payload. The OMI project is managed by NIVR and KNMI in the Netherlands. Thanks to the South African Weather Service for the support of the aeroplane and the logistical support in Bethlehem, including the daily weather briefing.

Edited by: M. Van Roozendael

\section{References}

Bobrowski, N., von Glasow, R., Aiuppa, A., Inguaggiato, S., Louban, I., Ibrahim, O. W., and Platt, U.: Reactive Halogen Chemistry in Volcanic Plumes, J. Geophys. Res., 112, D06311, doi:10.1029/2006JD007206, 2007.

Beirle, S., Platt, U., von Glasow, R., Wenig, M., and Wagner, T.: Estimate of nitrogen oxide emission from shipping by satellite remote sensing, Geophys. Res. Lett., 31, L18102, doi:10.1029/2004GL020312, 2004.

Beirle, S., Platt, U., and Wagner, T.: Potential of monitoring nitrogen oxides with satellite instruments, Procceeding of The 2006 EUMETSAT Meteorological Satellite Conference, Helsinki, Finland, http://www.eumetsat.int/Home/Main/Publications/ 
Conference_and_Workshop_Proceedings/groups/cps/documents/ document/pdf_conf_p48_s4_02_beirle_v.pdf, 12-16 June 2006.

Burrows, J. P., Richter, A., Dehn, A., Deters, B., Himmelmann, S., Voigt, S., and Orphal, J.: Atmospheric remote-sensing reference data from GOME: Part 2. Temperature-dependent absorption cross-sections of $\mathrm{O}_{3}$ in the 231-794 nm range, J. Quant. Spectrosc. Ra., 61, 509-517, 1999.

Deutschmann, T. and Wagner, T.: Tracy User manual, Universität Heidelberg, 2007.

Grainger, J. and Ring, J.: Anomalous Fraunhofer line profiles, Nature, 193, 762, 1962.

Gomer, T., Brauers, T., Heintz, F., Stutz, J., and Platt, U.: MFC 1.98 m User Manual, Institut für Umweltphysik, 1996.

Hartl, A., Song, B. C., and Pundt, I.: 2-D reconstruction of atmospheric concentration peaks from horizontal long path DOAS tomographic measurements: parametrisation and geometry within a discrete approach, Atmos. Chem. Phys., 6, 847-861, 2006, http://www.atmos-chem-phys.net/6/847/2006/.

Heue, K.-P., Richter, A., Bruns, M., Burrows, J. P., v. Friedeburg, C., Platt, U., Pundt, I., Wang, P., and Wagner, T.: Validation of SCIAMACHY tropospheric $\mathrm{NO}_{2}$-columns with AMAXDOAS measurements, Atmos. Chem. Phys., 5, 1039-1051, 2005, http://www.atmos-chem-phys.net/5/1039/2005/.

Heue, K.-P., Wagner, T., Broccardo, S. P., Piketh, S. J., Ross, K. E., and Platt, U.: Direct Observation of two dimensional trace gas distribution with an airborne Imaging DOAS instrument, Proceedings of the ESA Conference on Rockets and Balloons and related research, 4th-7th June 2007, Visby, Sweden, 2007.
Hermans, C., Vandaele, A. C., Carleer, M., Fally, S., Colin, R., Jenouvrier, A., Coquart, B., and Mérienne, M. F.: Absorptioncross sections of atmospheric constituents: $\mathrm{NO}_{2}, \mathrm{O}_{2}$ and $\mathrm{H}_{2} \mathrm{O}$, Environ. Sci. Pollut. Res., 6(3), 151-158, 1999.

Lohberger, F., Hönninger, G., and Platt, U.: Ground-based imaging differential optical absorption spectroscopy of atmospheric gases, Appl. Optics, 43, 24, 4711-4717, 2004.

Rothman, L. S.: The HITRAN molecular spectroscopic database and HAWKS (HITRAN Atmospheric Workstation): 1996 edition, J. Quant. Spectrosc. Ra., 60(5), 665-710, 1998.

Platt, U.: Differential Optical Absorbtion Spectroscopy (DOAS), in: Monitorting by spectroscopic techniques, edited by: Sigrist, M. W., New York: John Wiley \& Sons, Inc., 1994.

Vandaele, A. C., Hermans, C., Simon, P. C., Carleer, M., Colin, R., Fally, S., Mérienne, M.-F., Jenouvrier, A., and Coquart, B.: Measurements of the $\mathrm{NO}_{2}$ Absorption Cross-section from $42000 \mathrm{~cm}^{-1}$ to $10000 \mathrm{~cm}^{-1}(238-1000 \mathrm{~nm})$ at $220 \mathrm{~K}$ and 294 K, J. Quant. Spectrosc. Ra., 59, 171-184, 1997.

Wagner, T., Burrows, J. P., Deutschmann, T., Dix, B., von Friedeburg, C., Frieß, U., Hendrick, F., Heue, K.-P., Irie, H., Iwabuchi, H., Kanaya, Y., Keller, J., McLinden, C. A., Oetjen, H., Palazzi, E., Petritoli, A., Platt, U., Postylyakov, O., Pukite, J., Richter, A., van Roozendael, M., Rozanov, A., Rozanov, V., Sinreich, R., Sanghavi, S., and Wittrock, F.: Comparison of box-airmass-factors and radiances for Multiple-Axis Differential Optical Absorption Spectroscopy (MAX-DOAS) geometries calculated from different UV/visible radiative transfer models, Atmos. Chem. Phys., 7, 1809-1833, 2007, http://www.atmos-chem-phys.net/7/1809/2007/. 